\title{
The Concentration of Synaptically Released Glutamate Outside of the Climbing Fiber-Purkinje Cell Synaptic Cleft
}

\author{
Jeffrey A. Dzubay and Craig E. Jahr \\ Vollum Institute, Neuroscience Graduate Program, Oregon Health Sciences University, Portland, Oregon 97201
}

\begin{abstract}
AMPA receptors and glutamate transporters expressed by cerebellar Bergmann glial cells are activated by neurotransmitter released from climbing fibers (Bergles et al., 1997). Based on anatomical evidence, this is most likely the result of glutamate diffusing out of the climbing fiber-Purkinje cell synaptic clefts (Palay and Chan-Palay, 1974). We used the change in the $\mathrm{EC}_{50}$ of the Bergmann glia AMPA receptors produced by cyclothiazide (CTZ) to estimate the concentration of glutamate reached at the glial membrane. The decrease of the $\mathrm{EC}_{50}$ gives rise to a concentration-dependent potentiation of the AMPA receptormediated responses (Patneau et al., 1993). By comparing the increase in amplitude of the AMPA receptor response in the
\end{abstract}

Vesicular release of the neurotransmitter glutamate from presynaptic terminals results in millimolar levels of glutamate in the synaptic cleft (Clements et al., 1992; Clements, 1996; Diamond and Jahr, 1997). The close apposition of the presynaptic and postsynaptic membranes limits the dilution of neurotransmitter before reaching the postsynaptic receptors and thereby ensures that a high concentration of glutamate activates these receptors. The actions of the glutamate that diff uses out of the synaptic cleft are less clear. Eventually, high affinity $\mathrm{Na}^{+}$-dependent transporters in the surrounding membranes take up the glutamate (Nicholls and Attwell, 1990; Kanai et al., 1993). Although glutamate transporters are capable of reducing extracellular glutamate to submicromolar levels, attaining such low concentrations is not instantaneous (Zerangue and Kavanaugh, 1996). For example, release of glutamate at excitatory synapses in both cerebellum and hippocampus results in transporter activation in surrounding glia for >10 msec (Bergles and Jahr, 1997; Bergles et al., 1997; Clark and Barbour, 1997). The concentration reached outside of parallel and climbing fiber synapses on cerebellar Purkinje cells is sufficient to activate low-affinity AMPA receptors on the surrounding Bergmann glia (Bergles et al., 1997; Clark and Barbour, 1997).

The emerging picture of the perisynaptic space is that of a region in which the concentration of transmitter can be transiently elevated with synaptic activity. These increases in extrasynaptic glutamate can result in modulation of synaptic transmission via

\footnotetext{
Received Nov. 24, 1998; revised March 29, 1999; accepted April 19, 1999.

This work was supported by National Institutes of Health Grants MH11978 (J.A.D.) and NS21419 (C.E.J.). We thank Drs. Dwight Bergles, Jeff Diamond, and Jacques Wadiche for a critical reading of this manuscript and their helpful comments. A special thanks to Dr. Tom Otis for initial experimental ideas and to Dr. Michael Häusser for help with the voltage jump analysis and NEURON simulation.

Correspondence should be addressed to Craig E. Jahr, Vollum Institute L474, Oregon Health Sciences University, 3181 S.W. Sam Jackson Park Road, Portland, OR 97201-3098.

Copyright (C) 1999 Society for Neuroscience $\quad 0270-6474 / 99 / 195265-10 \$ 05.00 / 0$
}

Bergmann glia ( $840 \pm 240 \% ; n=8)$ with the shift in the glutamate dose-response curve measured in excised patches $\left(\mathrm{EC}_{50}, 1810 \mu \mathrm{m}\right.$ in control vs $304 \mu \mathrm{M}$ in CTZ), we estimate that the extrasynaptic transmitter concentration reaches 160-190 $\mu \mathrm{M}$. This contrasts with the concentration in the synaptic cleft, thought to rapidly rise above $1 \mathrm{~mm}$, but is still high enough to activate glutamate receptors. These results indicate that the sphere of influence of synaptically released glutamate can extend beyond the synaptic cleft.

Key words: ion channels; AMPA receptors; glutamate transporters; glutamate; extrasynaptic; glia activation of both metabotropic (Scanziani et al., 1997) and ionotropic (Clarke et al., 1997) receptors. The concentration of glutamate reached outside of the cleft after synaptic release is critical in determining the extent of extrasynaptic receptor activation. Recent estimates based on the concentration dependence of the kinetics of AMPA receptor responses in outside-out patches indicated that the glutamate concentration peaks at $<250 \mu \mathrm{M}$ at the Bergmann glia membranes (Bergles et al., 1997). However, the responses below this concentration were too small to analyze, limiting the measurement. By using cyclothiazide (CTZ) to alter the dose-response relationship of glutamate at Bergmann glia AMPA receptors, we report that the glutamate concentration transiently peaks at $160-190 \mu \mathrm{M}$ in the extrasynaptic space. This concentration is sufficient for activation of perisynaptic glutamate receptors.

\section{MATERIALS AND METHODS}

Slices and solutions. Parasagittal slices of 13- to 15-d-old rat cerebella were cut at a thickness of $300 \mu \mathrm{m}$ using a vibratome in an ice-cold external solution containing (in $\mathrm{mM}$ ): $119 \mathrm{NaCl}, 2.5 \mathrm{KCl}, 2.5 \mathrm{CaCl}_{2}, 1.3$ $\mathrm{MgCl}_{2}, 1 \mathrm{NaH}_{2} \mathrm{PO}_{4}, 26.2 \mathrm{NaHCO}_{3}$, and 11 glucose, bubbled with $95 \%$ $\mathrm{O}_{2}-5 \% \mathrm{CO}_{2}$. The slices were placed in the same solution warmed to $34^{\circ} \mathrm{C}$ for $15-30 \mathrm{~min}$ and then stored at room temperature. During recordings, the slices were perfused with the above solution with the addition of $100 \mu \mathrm{M}$ picrotoxin and $5 \mu \mathrm{M}$ (DL)-3-(2-carboxypiperazin-4-yl)-propyl-1phosphonic acid (CPP). Patch experiments were performed in the presence of $200 \mu \mathrm{M}$ DL-threo- $\beta$-hydroxy-aspartic acid (THA) to isolate the AMPA receptor response, with an extracellular solution containing (in mM): $135 \mathrm{NaCl}, 5.4 \mathrm{KCl}, 5 \mathrm{HEPES}, 1.8 \mathrm{CaCl}_{2}$, and $1.3 \mathrm{MgCl}_{2}, \mathrm{pH}$ 7.4. THA has been shown previously to have no direct effect on AMPA receptors (Tong and Jahr, 1994). For the synaptic and dose-response experiments in Bergmann glia, the pipette solutions contained (in $\mathrm{mM}$ ): $130 \mathrm{KNO}_{3}, 20 \mathrm{HEPES}, 10 \mathrm{EGTA}$, and $1 \mathrm{MgCl}_{2}$, $\mathrm{pH}$ 7.2. For the voltage jump experiments, the internal solution had (in $\mathrm{mM}$ ): $100 \mathrm{Cs}-$ methanesulfonate, 20 TEA-Cl, 20 HEPES, 10 EGTA, $1 \mathrm{MgCl}_{2}, 3.1$ Mg-ATP, $0.3 \mathrm{Na}_{2}$-GTP, and 4 phosphocreatine, $\mathrm{pH} 7.2$; this solution 
approximately doubled the input resistance $\left(28 \pm 14 \mathrm{M} \Omega\right.$ with $\mathrm{KNO}_{3}$ to $58 \pm 18 \mathrm{M} \Omega$ with Cs-methanesulfonate). For the synaptic and patch experiments in Purkinje cells, the pipette solution contained (in $\mathrm{mM}$ ): 107.5 Cs-gluconate, 10 TEA-Cl, 20 HEPES, 10 EGTA, 0.3 Na2-GTP, 4 $\mathrm{Mg}$-ATP, and $8 \mathrm{NaCl}, \mathrm{pH} 7.2$. The sources of the chemicals are as follows: L-glutamate, HEPES, EGTA, Mg-ATP, phosphocreatine, THA, $\mathrm{CaCl}_{2}$, and $\mathrm{MgCl}_{2}$ (Sigma, St. Louis, $\mathrm{MO}$ ); $\mathrm{NaCl}, \mathrm{KCl}, \mathrm{NaH}_{2} \mathrm{PO}_{4}, \mathrm{NaHCO}_{3}$, and glucose (Mallinckrodt, Paris, Kentucky); $\mathrm{Na}_{2}$-GTP (Boehringer Mannheim, Mannheim, Germany); 6-nitro-7-sulfamoylbenzo[f]quinoxaline-2,3dione (NBQX) (Tocris, Ballwin, MO); CPP, CTZ, and picrotoxin, (Research Biochemicals, Natick, MA).

Recording and perfusion techniques. Bergmann glia were identified by their size $(\sim 10 \mu \mathrm{m}$ soma diameter) and location (near the Purkinje cell bodies) using a $40 \times$ water-immersion objective on an upright microscope (Axioskop; Zeiss, Oberkochen, Germany) equipped with infrared-differential interference contrast optics. Further confirmation of their identity was provided by their large negative membrane potential ( -90 to $-80 \mathrm{mV})$, low input resistance $\left(28 \pm 14 \mathrm{M} \Omega\right.$ with $\left.\mathrm{KNO}_{3}\right)$, and lack of action potentials. Bergmann glia currents were recorded at their resting potential. Purkinje cell bodies were identified by their large size (20-30 $\mu \mathrm{m})$, layered arrangement, and large dendritic tree. Purkinje cell EPSCs were recorded at approximately $-10 \mathrm{mV}$ to minimize the current amplitude. Patch pipettes were pulled from World Precision Instruments (Sarasota, FL) glass number PG10165-4 and had resistances of 1.5-3 $\mathrm{M} \Omega$. Climbing fibers were stimulated with a theta glass pipette (catalog \#TGC150-10; Warner Instruments, Hamden, CT) pulled to a 4-6 $\mu \mathrm{m}$ tip and filled with external solution. The stimulating electrode was placed in the granule cell layer between 10 and $50 \mu \mathrm{m}$ from the Purkinje cell layer. A constant current stimulator (Weco, Millbrae, CA) was used to supply a $100 \mu \mathrm{sec}$ pulse of $10-100 \mu \mathrm{A}$. The pipette was repositioned, and stimulus intensity was adjusted until the current required to elicit an all or none response was minimized. This was done to eliminate any significant parallel fiber activation. We tested for parallel fiber activation by stimulating at an intensity near threshold that produced some climbing fiber failures and only proceeded when the failures were complete; that is, when no residual response was evident. Synaptic currents were filtered at $1 \mathrm{kHz}$ and sampled at $10 \mathrm{kHz}$, and outside-out patch currents were filtered at $2-5 \mathrm{kHz}$ and sampled at $50 \mathrm{kHz}$. A theta glass flow-pipe mounted on a piezoelectric bimorph (Vernitron, Bedford, $\mathrm{OH}$ ) was used for agonist applications to outside-out patches as described previously (Lester and Jahr, 1992; Tong and Jahr, 1994). The ability to change the solution flowing through both sides of the flow-pipe was added via miniature manifolds (Warner Instruments). The solutions were allowed to flow for at least 2 min between conditions to allow complete exchange through the manifold and tubing. Two to three concentrations with and without CTZ present were tested in each patch, and the amplitudes were normalized to the response to $3 \mathrm{~mm}$ glutamate without CTZ. Data were acquired, and some analysis was done using AXOBASIC software (Axon Instruments, Foster City, CA), and further analysis was preformed using Origin 5.0 (Microcal Software, Northampton, MA), Igor Pro (Wavemetrics, Lake Oswego, OR), and InStat (Graph Pad Software, San Diego, CA). Most experiments were performed at room temperature $\left(22-24^{\circ} \mathrm{C}\right)$. In some experiments, the bath temperature was elevated with an in-line heating device (Warner Instruments). Values are given as mean $\pm \mathrm{SD}$, and $p$ values are for paired Student's $t$ tests unless noted otherwise.

Voltage jump protocol. A novel method to estimate the time course of synaptic conductances introduced by Pearce (1993) has been formalized by Häusser and Roth (1997), and the experiments illustrated in Figure 6 were based on that method. Each trial consisted of a single climbing fiber stimulation combined with a voltage step from -50 to $-80 \mathrm{mV}$. There were 32 trials in a single run through the experiment, and the voltage was stepped at a different time in each trial; $1 \mathrm{msec}$ increments were used at times near the climbing fiber stimulus, and $4 \mathrm{msec}$ increments were used at earlier and later times. The process was repeated several times (5-14) for averaging purposes, and $200 \mu \mathrm{M} \mathrm{CTZ}$ was used to increase the size of the currents. Interleaved voltage jump trials without synaptic stimulation were subtracted, and the charge transfer was calculated by integration. The recovered charge was plotted versus time relative to the stimulation. The resulting curve was fitted with the following equation, where $s$ is the time of the jump relative to the stimulus, $\tau_{\text {epscrise }}$ and $\tau_{\text {epscdecay }}$ are the time constants of the conductance approximated by the sum of two exponentials, $\tau_{\mathrm{v}}$ is the time constant of the voltage change at the con- ductance, $A$ is a constant, and $Q$ is the recovered charge. For $s \leq 0$

$Q=A\left(\tau_{\text {epscrise }}-\tau_{\text {epscdecay }}+e^{S / \tau_{v}}\left(\frac{1}{1 / \tau_{\text {epscdecay }}+1 / \tau_{v}}\right.\right.$ $\left.\left.-\frac{1}{1 / \tau_{\text {epscrise }}+1 / \tau_{v}}\right)\right)$

For $s>0$

$Q=A\left(\tau_{\text {epscrise }} e^{-S / \tau_{\text {epserise }}}-\tau_{\text {epscdecay }} e^{-S / \tau_{\text {epscdecay }}}+\frac{e^{-S / \tau_{\text {epscdecay }}}}{1 / \tau_{\text {epscdecay }}+1 / \tau_{v}}\right.$
$\left.-\frac{e^{-S / \tau_{\text {epscrise }}}}{1 / \tau_{\text {epscrise }}+1 / \tau_{v}}\right)$

The fits were performed using custom Igor macros written by Dr. Michael Häusser (Department of Physiology, University College London, London, UK). Two controls were performed to confirm the linearity of the membrane between -50 and $-80 \mathrm{mV}$. Holding at $-70 \mathrm{mV}$ and stepping $\pm 5,10,15$, and $20 \mathrm{mV}$ resulted in currents that overlapped exactly when scaled by the command voltage (data not shown). In addition, Bergmann glia AMPA receptor responses recorded at $50 \mathrm{mV}$ had the same time course as those recorded at $-80 \mathrm{mV}$ (see Fig. 6C).

NEURON simulation. Using the Windows version of the program NEURON (Hines, 1993), a template for a Bergmann glial cell was constructed with the following parameters: soma, $10 \mu \mathrm{m}$ long, $10 \mu \mathrm{m}$ diameter, 10 segments; 12 processes, $300 \mu \mathrm{m}$ long, $0.5 \mu \mathrm{m}$ diameter, 100 segments; and end feet, $5 \mu \mathrm{m}$ long, $5 \mu \mathrm{m}$ diameter, 10 segments (Palay and Chan-Palay, 1974; de Blas, 1984; Bergles et al., 1997). Two identical neighboring cells were connected to the recorded cell via cylinders $1 \mu \mathrm{m}$ long and $1 \mu \mathrm{m}$ in diameter. The electrical parameters were $R_{\mathrm{a}}=150$ $\Omega \cdot \mathrm{cm}, C_{\mathrm{m}}=1 \mu \mathrm{F} / \mathrm{cm}^{2}$, and $g_{\mathrm{m}}=100 \mu \mathrm{S} / \mathrm{cm}^{2}$ in the soma and processes, and $g_{\mathrm{m}}=500 \mu \mathrm{S} / \mathrm{cm}^{2}$ in the end feet for simulations of recordings using the Cs-methanesulfonate-based internal solution. For the $\mathrm{KNO}_{3}$-based internal solution, the passive membrane conductances were made four times higher. The reversal potential for the passive conductances was set at $-90 \mathrm{mV}$.

The model parameters above were determined by an iterative process. In addition to the general morphology of the Bergmann glial cell (Palay and Chan-Palay, 1974; de Blas, 1984; Bergles et al., 1997), the passive response of the Bergmann glia to a square $1 \mathrm{nA}$ current injection was reproduced along with the amount of filtering estimated by the Häusser voltage jump analysis. The simulated passive response was constrained to an input resistance of $28 \mathrm{M} \Omega$ and a single exponential rise of $1.4 \mathrm{msec}$ using the $\mathrm{KNO}_{3}$ internal solution. With the Cs-methanesulfonate solution, the rise was $5.8 \mathrm{msec}$, and the input resistance was $59 \mathrm{M} \Omega$. The simulation was further constrained to filter a synaptic conductance that decays with a tau of $5.9 \mathrm{msec}$ such that the EPSC recorded at the soma decays with a tau of $8.4 \mathrm{msec}$, using the Cs-methanesulfonate internal solution. The synaptic conductance was simulated with a point process consisting of a sum of one rising and one decaying exponential placed on each process. The location of the synapse was one of the parameters altered in the development of the model, and in the final model each synapse was located $210 \mu \mathrm{m}$ from the soma.

This model was used to estimate the error in the peak amplitude of the Bergmann glia AMPA receptor response to climbing fiber stimulation in the presence and absence of CTZ. To reproduce the experimental data, the synaptic conductance parameters were set as follows: in CTZ, $\tau_{\text {rise }}=$ $1.22 \mathrm{msec}, \tau_{\text {decay }}=8.34 \mathrm{msec}$, and $g_{\max }=570 \mathrm{pS}$; and in control, $\tau_{\text {rise }}=$ 0.4 and $0.7 \mathrm{msec}, \tau_{\text {decay }}=3.85 \mathrm{msec}$, and $g_{\max }=67$ and $64 \mathrm{pS}$. A range of values was used for the rise time in control because it was not uniquely defined by the system; values down to $100 \mu \mathrm{sec}$ were slowed by cable filtering to near the $0.83 \pm 0.27 \mathrm{msec} 20-80 \%$ rise time measured at the soma. In patches from Bergmann glia somata, the $20-80 \%$ rise time of a response to $250 \mu \mathrm{M}$ glutamate was $0.6 \mathrm{msec}$ (Bergles et al., 1997). Thus, a range at approximately this value was used for the synaptic conductance to account for differences in concentration and speed of agonist application.

AMPA receptor kinetic model. To simulate the activation of the AMPA receptor by glutamate, a kinetic model of the AMPA receptor (see Fig. $8 A$ ) was developed using Simulation Control Program (Simulation Resources, Berrien Springs, MI). Details of the model are given in Results and in the legend of Figure 8. 
A

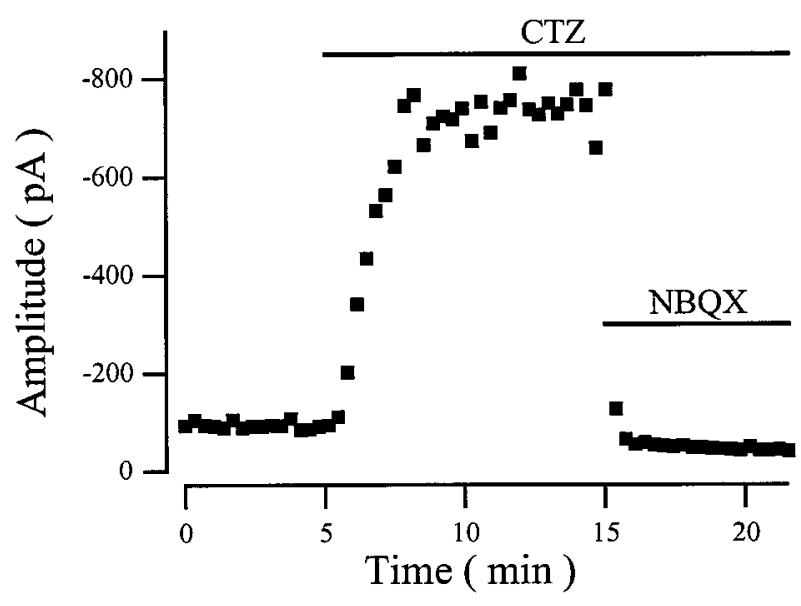

B
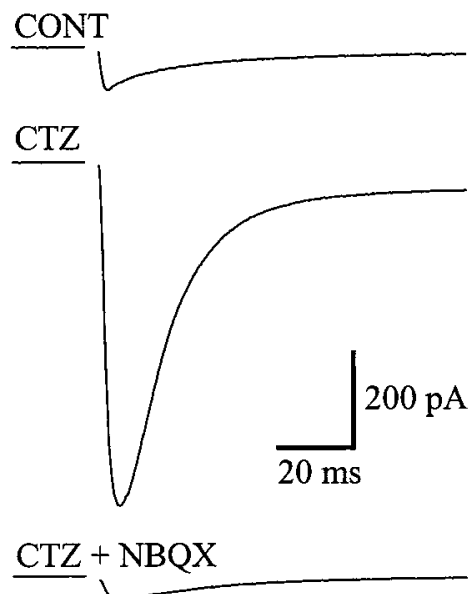
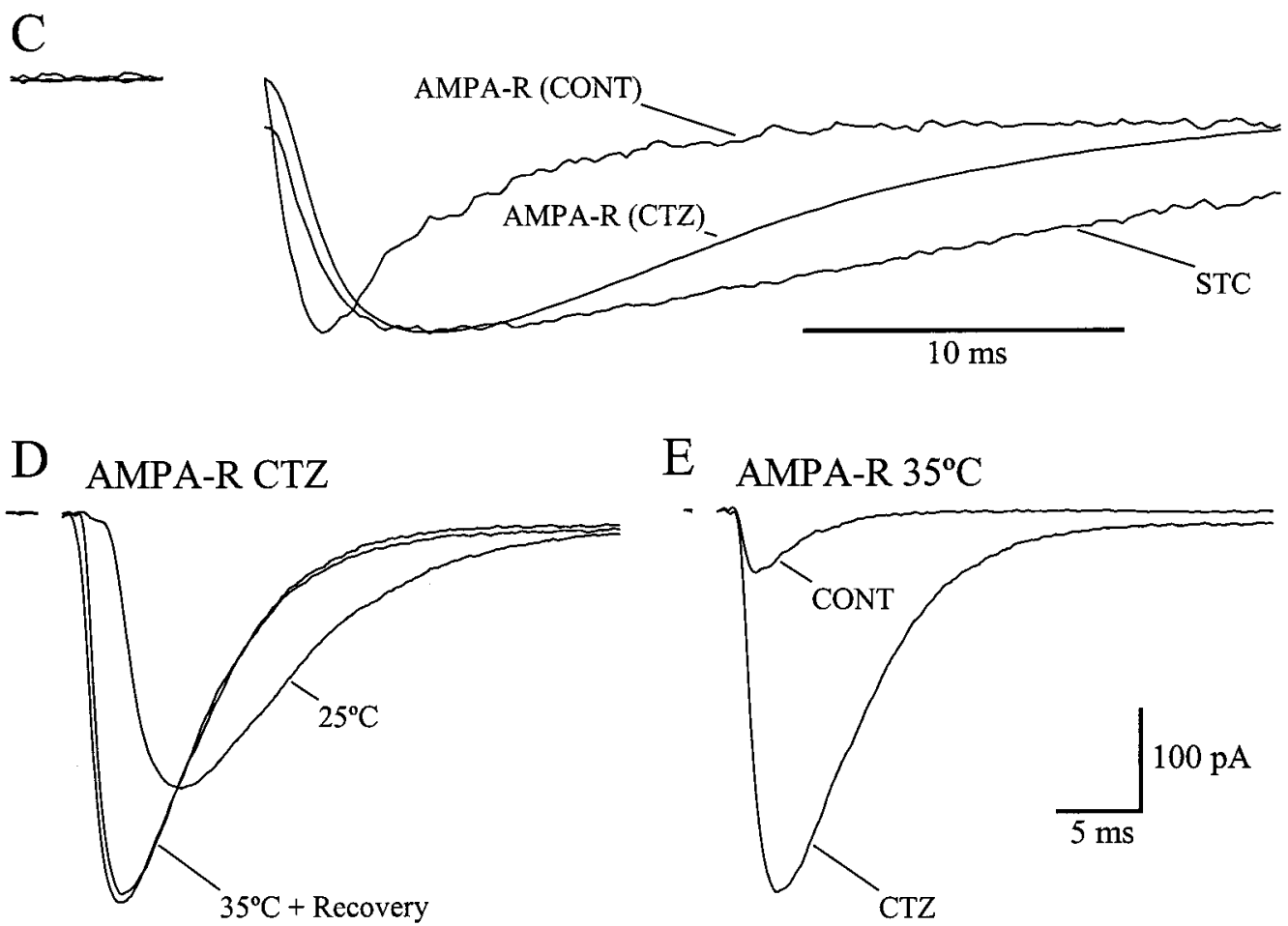

E AMPA-R $35^{\circ} \mathrm{C}$

$-$

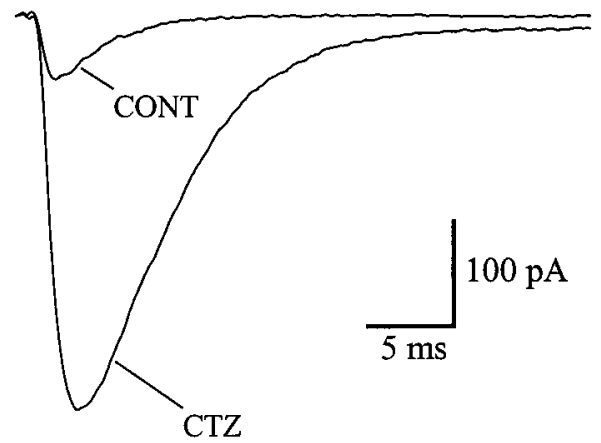

Figure 1. The effects of CTZ and temperature on the response of the Bergmann glial cell to climbing fiber activation. $A$, A plot of the peak amplitude of the Bergmann response to climbing fiber stimulation every $20 \mathrm{sec}$. After $5 \mathrm{~min}$ of stable baseline, $200 \mu \mathrm{M}$ CTZ was applied in the perfusate, followed $10 \mathrm{~min}$ later by $10 \mu \mathrm{M}$ NBQX. The resting-holding potential of the cell was $-88 \mathrm{mV}$. $B$, Averages of five sweeps under control conditions, in CTZ, and in NBQX. $C$, Comparison of the time course of the different components of the response isolated by subtraction of the synaptically activated transporter current $(S T C)$, the current remaining in NBQX. Averages of five sweeps were scaled to their peaks. $D$, The AMPA receptor-mediated response in CTZ at $35^{\circ} \mathrm{C}$, at $25^{\circ} \mathrm{C}$, and again at $35^{\circ} \mathrm{C}$. E. The AMPA receptor-mediated response (STC subtracted) at $35^{\circ} \mathrm{C}$ under control $(C O N T)$ conditions and with $200 \mu \mathrm{M}$ CTZ present $(C T Z)$. The responses in $D$ and $E$ are from a different cell than in $A-C$ and are averages of five responses. This resting-holding potential of the cell was $-82 \mathrm{mV}$.

\section{RESULTS}

\section{CTZ increases the Bergmann glia AMPA receptor response}

CTZ increases the apparent affinity of AMPA receptors (Patneau et al., 1993; Yamada and Tang, 1993; Partin et al., 1994, 1996). We used this property of CTZ to measure the concentration of glutamate reaching the AMPA receptors in the Bergmann glial cell membrane.
As reported previously (Bergles et al., 1997), climbing fiber stimulation in cerebellar slices activates currents in Bergmann glia mediated by both AMPA receptors and glutamate transporters. After establishing a stable baseline of the combined AMPA receptor-transporter current for $5 \mathrm{~min}$ (stimulating every 15-20 sec), a saturating concentration of CTZ $(200 \mu \mathrm{M})$ was applied while continuing to stimulate. Over a period of minutes, the amplitude of the response increased dramatically (Fig. 1A,B). 
After the response stabilized, the AMPA receptor antagonist NBQX $(10 \mu \mathrm{M})$ was applied to isolate the transporter current (Fig. 1A,B) (Bergles et al., 1997; Clark and Barbour, 1997). Separation of the AMPA receptor-mediated response in the presence and absence of CTZ was achieved by subtracting the transporter current from the combined responses (Fig. 1C). For this subtraction to be valid, the transporter current must be unaffected by CTZ, as will be shown below.

CTZ increased the peak amplitude of the AMPA receptor component $840 \pm 240 \%(p<0.0001 ; n=8)$ and slowed the time course. The $20-80 \%$ rise time of the response in CTZ was $1.6 \pm$ $0.5 \mathrm{msec}$ compared with $0.8 \pm 0.3 \mathrm{msec}$ for the control response, and the half-decay time was $9.4 \pm 2.8 \mathrm{msec}$ in CTZ versus $4.3 \pm$ $2.9 \mathrm{msec}$ in control $(n=8)$. This slowing is caused by, at least in part, the relief of desensitization that, under control conditions, is likely to truncate the rising phase and speed the decay of the response. An increased affinity would also prolong the response, as receptors may remain occupied longer and be sensitive to lower concentrations of glutamate diffusing to more remote receptors.

There is evidence that the effects of extrasynaptic glutamate are reduced at physiological temperatures (Asztely et al., 1997; Kullmann and Asztely, 1998). The strong temperature dependence of transport (Wadiche et al., 1995) and the expression of glutamate transporters in the postsynaptic Purkinje cells (Rothstein et al., 1994) may decrease the glutamate diffusing to the Bergmann glia membranes at physiological temperatures. However, consistent with the hippocampal astrocyte recordings of Bergles and Jahr (1998), the glial transporter and AMPA receptor-mediated currents were present in the Bergmann astrocytes at elevated temperatures. Raising the bath temperature from 25 to $35^{\circ} \mathrm{C}$ slightly increased the amplitude and speeded the kinetics of the Bergmann glia responses (Fig. $1 D$ ). At $35^{\circ} \mathrm{C}$, the $20-80 \%$ rise time and half-decay time for the control AMPA receptor-mediated responses were $0.6 \pm 0.2$ and $3.0 \pm 1.9 \mathrm{msec}$ respectively, and in $200 \mu \mathrm{M}, \mathrm{CTZ}$ they were $0.8 \pm 0.1$ and $5.5 \pm$ $0.3 \mathrm{msec}(n=3)$. The effect of CTZ on the amplitude of the AMPA receptor-mediated response at $35^{\circ} \mathrm{C}$ was not significantly different from that seen at room temperature $(740 \pm 150 \%$ increase; $p=0.53$; unpaired $t$ test) (Fig. $1 E$ ). The remainder of the experiments were performed at room temperature.

\section{The Bergmann glia transporter current as a monitor of climbing fiber release probability}

There is evidence that, at some synapses, CTZ can increase the probability of release (Barnes-Davies and Forsythe, 1995; Diamond and Jahr, 1995), which would complicate our analysis of transmitter concentration. Several findings indicate that CTZ alters climbing fiber release probability very little. First, the paired-pulse ratio (30 msec interval) of the Bergmann glia AMPA receptor-mediated response to climbing fiber activation was unaffected by CTZ $(0.15 \pm 0.08$ in control vs $0.14 \pm 0.06$ in $\mathrm{CTZ} ; p=0.60 ; n=7)$. Second, the transporter currents recorded at the end of experiments in which CTZ was present were the same proportion of the initial control dual-component response as those recorded at the end of experiments in the absence of CTZ $(40.4 \pm 18.3 \% ; n=8$; vs $44.3 \pm 13.4 \% ; n=17 ; p=0.55$; unpaired $t$ test). Third, the transporter current isolated with NBQX was not affected by the addition of $200 \mu \mathrm{M} \mathrm{CTZ} \mathrm{(101 \pm}$ $10 \%$ of control $p=0.94 ; n=3$ ) (Fig. $2 A$ ). These results suggest that the probability of release is not altered by CTZ at this synapse. However, it is possible that the transporter current is insensitive to changes in release because of saturation of the
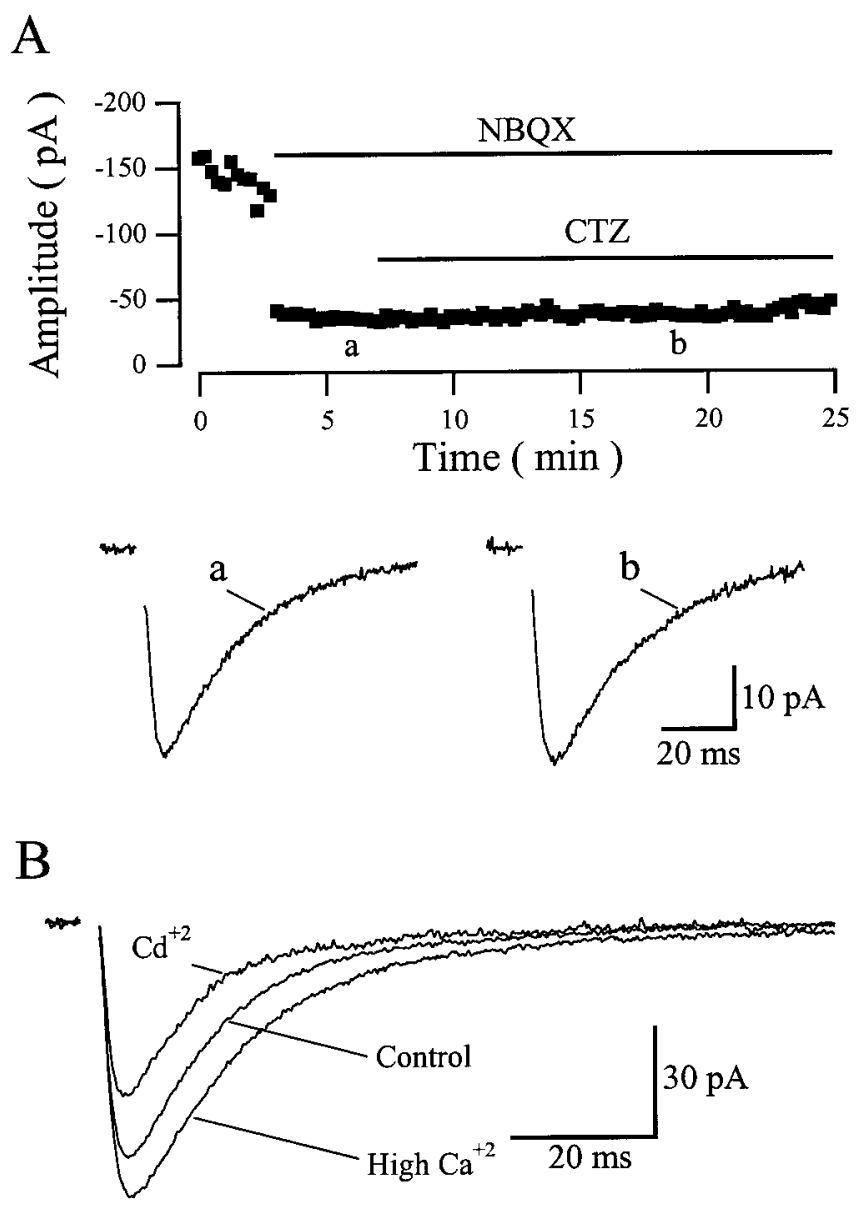

Figure 2. The Bergmann glia transporter current indicates no effect of CTZ on climbing fiber release. A, Top, Peak amplitude plot of the Bergmann glia response. The AMPA response was blocked with $10 \mu \mathrm{M}$ NBQX, and no increase in amplitude of the remaining transport current was seen after application of $200 \mu \mathrm{M}$ CTZ. Bottom, Averages of 10 traces, with the last trace located at the time points indicated in the amplitude plot. The membrane potential of the cell was $-80 \mathrm{mV}$. $B$, The transporter current (isolated with $10 \mu \mathrm{M} \mathrm{NBQX)}$ of a different cell showing the effects of adding $5 \mu \mathrm{M} \mathrm{Cd}^{+2}$ or $5 \mathrm{mM} \mathrm{Ca}^{+2}$ to the external solution. Averages of 5-15 traces. The membrane potential of this cell was $-78 \mathrm{mV}$.

transporters. To demonstrate that they are sensitive to such changes, the release probability was altered while monitoring the transporter current (Fig. $2 B$ ). Transporter currents were reduced to $63 \pm 12 \%$ of control $(p<0.0001 ; n=8)$ by adding $5 \mu \mathrm{M} \mathrm{CdCl}_{2}$ and increased to $116 \pm 3 \%$ of control $(p<0.003 ; n=4)$ by raising external $\mathrm{Ca}^{+2}$ to $7.5 \mathrm{~mm}$. A large increase was not expected because the probability of release at this synapse is already very high (Dittman and Regehr, 1998; Silver et al., 1998).

\section{Purkinje cell AMPA receptor response as a monitor of climbing fiber release probability}

CTZ was also ineffective in altering the climbing fiber release probability as measured by Purkinje cell responses. The amplitude of the Purkinje cell EPSC resulting from climbing fiber stimulation was unchanged by application of $200 \mu \mathrm{M} \mathrm{CTZ} \mathrm{(100 \pm}$ $7 \%$ of control; $p=0.96 ; n=5$ ) (Fig. 3 ). The paired-pulse ratio of the climbing fiber-Purkinje cell EPSC was also not altered by CTZ $(0.44 \pm 0.16$ in control vs $0.38 \pm 0.06$ in CTZ; $p=0.46 ; n=$ 4) (Fig. 3C). Consistent with the lack of a CTZ effect on the amplitude of the Purkinje cell EPSCs, the amplitude of patch 
A

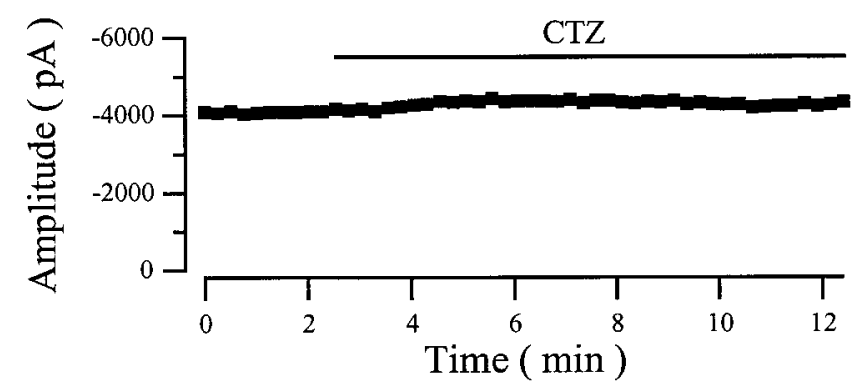

B

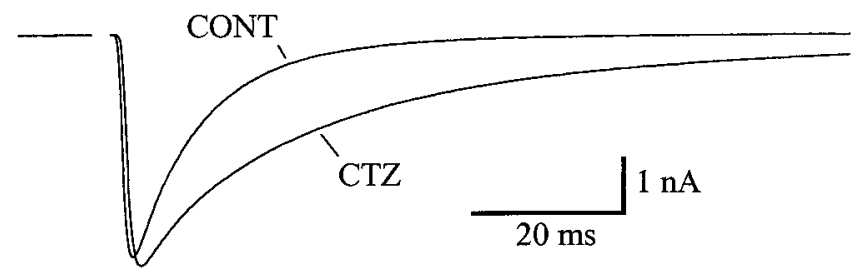

C
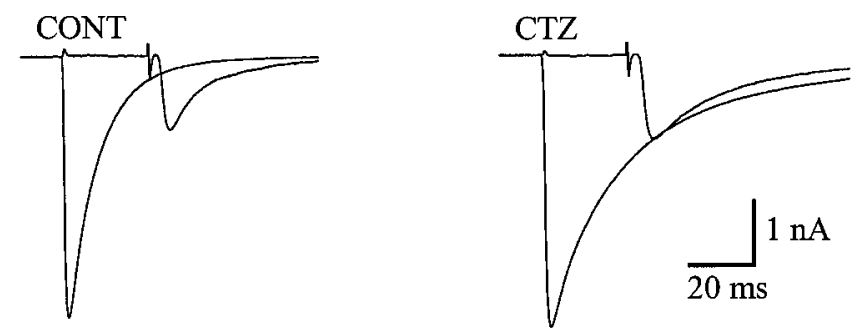

Figure 3. The Purkinje cell EPSC shows no increase of climbing fiber release in CTZ. A, Peak amplitude plot of the Purkinje cell EPSC evoked by climbing fiber stimulation. After a stable baseline period, $200 \mu \mathrm{M} \mathrm{CTZ}$ was added to the external solution. The cell was held at $-6 \mathrm{mV}$. $B$, Averages of five responses under control conditions and in the presence of $200 \mu \mathrm{M}$ CTZ. $C$, The above averages along with the second of a pair of responses isolated by subtraction of the single responses. The paired stimuli were delivered $30 \mathrm{msec}$ apart.

responses to a saturating dose $(3 \mathrm{~mm})$ of glutamate were also unaffected by CTZ $(109 \pm 10 \%$ of control; $p=0.55 ; n=4)$. These results argue that the large increase in amplitude of the Bergmann glia AMPA receptor response caused by CTZ is not the result of an increase in climbing fiber release probability but rather is caused by a direct effect of CTZ on the apparent affinity of the AMPA receptors.

\section{Estimation of transmitter concentration at the Bergmann glia membrane}

To estimate the peak transmitter concentration at Bergmann glia AMPA receptors, we have compared the CTZ-induced increase in peak amplitude of the climbing fiber response with the ratio of AMPA receptor dose-response relationships in the presence and absence of CTZ. Dose-response relationships were determined with rapid applications of glutamate to outside-out patches taken from Bergmann glia somata. CTZ caused a dose-dependent potentiation of the glutamate response, concomitant with a relief of receptor desensitization. As an example of the concentration dependence, the average response to $300 \mu \mathrm{M}$ glutamate was
A

$300 \mu \mathrm{M} \mathrm{GLU}$

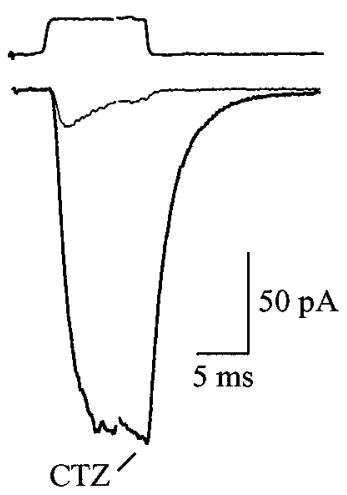

B

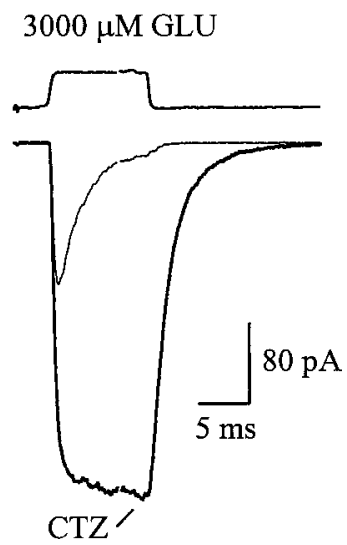

Figure 4. CTZ increased Bergmann glia patch responses to glutamate in a dose-dependent manner. Responses of an outside-out patch to $300(A)$ and $3000(B) \mu \mathrm{M}$ glutamate $(G L U)$ under control conditions (thin lines) and in the presence of $200 \mu \mathrm{M} \mathrm{CTZ}$ (thick lines). The $300 \mu \mathrm{M}$ response was increased 9.6-fold by CTZ, whereas the $3000 \mu \mathrm{M}$ response was only increased 2.5 -fold. The responses are averages of $20-40$ traces. To account for a small amount of rundown, the conditions were repeated two to three times interleaving the various conditions. The patch was held at $-80 \mathrm{mV}$. The applications were $10 \mathrm{msec}$ long and separated by $10 \mathrm{sec}$.

increased 7.0-fold, whereas the $3 \mathrm{~mm}$ response increased by only 2.3-fold (Fig. 4).

As shown in Figure $5 A$, there was an increase in both the apparent affinity for glutamate (control, $\mathrm{EC}_{50}=1810 \mu \mathrm{M}$; CTZ, $\left.\mathrm{EC}_{50}=304 \mu \mathrm{M}\right)$ and the maximal response (1.5-fold) in CTZ. Measurements were made at the peak of the responses. Using the ratio of the two dose-response curves, we generated a curve that indicates the expected fold increase in the receptor response for concentrations ranging from $3 \mu \mathrm{M}$ to $30 \mathrm{~mm}$ (Fig. $5 B$ ). The climbing fiber-evoked Bergmann glia response increased 8.4-fold, which corresponds to $192 \mu \mathrm{M}$ on the ratio curve. The $95 \%$ confidence interval for the fold increase is 10.4 to 6.4 , indicating a range of 80-372 $\mu \mathrm{M}$ glutamate. This estimation of the concentration of glutamate at the Bergmann glia AMPA receptors (190 $\mu \mathrm{M})$ is consistent with our earlier estimates $(<250 \mu \mathrm{M})$ based on a kinetic analysis (Bergles et al., 1997).

\section{Voltage jump analysis of somatic recordings}

In the presence of CTZ, AMPA receptor currents in patches do not desensitize (Fig. 4). If CTZ affects synaptically activated AMPA receptors on Bergmann glia similarly, the time course of the AMPA-mediated conductance should reflect the period over which clearance of glutamate from the extracellular space occurs. This is because the intrinsic kinetics of the receptors, as demonstrated by patch recordings (Fig. 4), are rapid relative to the synaptic responses (Bergles et al., 1997). To determine whether the current recorded at the soma accurately reflects the kinetics of the conductance, a voltage jump analysis introduced by Pearce (1993) and formalized by Häusser and Roth (1997) was used in the presence of CTZ. This method not only extracts information about the amount of filtering of the recorded signals but also gives an indication of the average electrotonic distance of the conductances from the soma.

The method is based on the observation that a change in the driving force will affect the amount of charge transfer only if it occurs during the active conductance. This is illustrated in Figure $6 A$, which shows the voltage jump procedure at three separate 


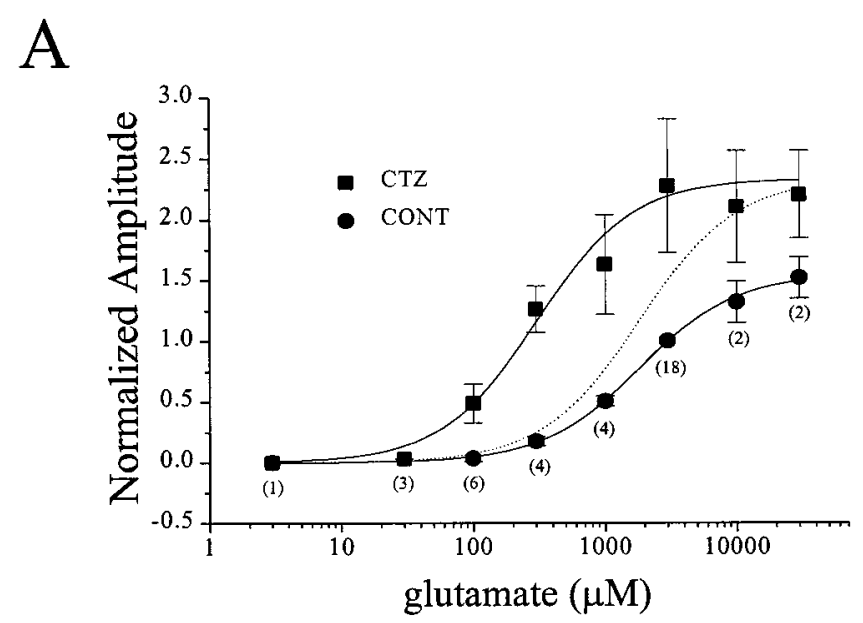

B

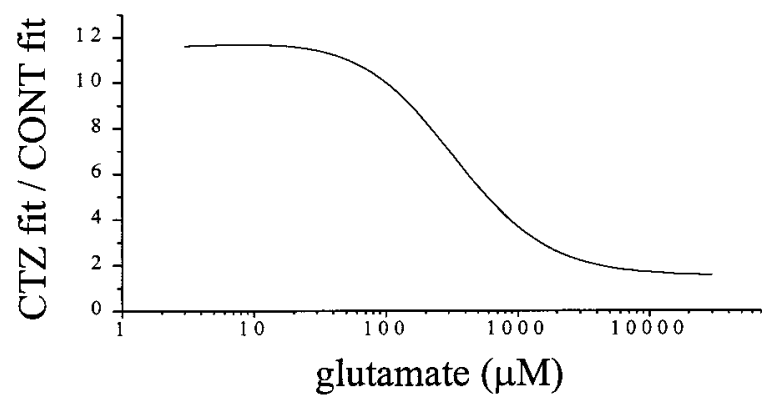

Figure 5. Quantification of the glutamate reaching the Bergmann glia AMPA receptors. $A$, Dose-response curves were constructed using data from a total of 18 patches. Two or three concentrations with or without CTZ were tested in each patch. The patch responses, including those in CTZ, were all normalized to $3 \mathrm{~mm}$ glutamate under control conditions. The control $\mathrm{EC}_{50}$ for glutamate was $1810 \mu \mathrm{M}$, and in the presence of CTZ it was $304 \mu \mathrm{M}$. The dotted line is the fit of the control data multiplied by the increase in maximal amplitude (1.5-fold), illustrating what the data would look like with no change in affinity. $B$, The ratio of the CTZ fit over the control fit plotted against concentration. The average fold increase of the Bergmann glia AMPA response (8.4-fold) falls at $192 \mu \mathrm{M}$ on the $x$-axis.

time points (relative to the synaptic stimulation) applied to a Bergmann glial cell in the presence of $200 \mu \mathrm{M}$ CTZ. In Figure $6 B$, the time integral of the AMPA receptor response (the charge transfer) is plotted versus the time at which the voltage was jumped. The charge recovery curves were made up of 32 time points; each point was an average of 5-14 measurements in a single cell. The curve was fitted with an analytical function (see Materials and Methods; Häusser and Roth, 1997) in which the exponential time constant for the charging of the membrane (at which the conductance occurs) and the decay of the synaptic conductance were allowed to vary. The smallest interval measured was $1 \mathrm{msec}$, so the time constant for the rise time was fixed at $1 \mathrm{msec}$ (a rise time of 0.5 or $1.5 \mathrm{msec}$ did not affect the results of the fitting).

The average time constant of the decay of the conductance calculated from the full analytical fit of the charge recovery curves was $5.9 \pm 1.6 \mathrm{msec}(n=7)$. This is not significantly different from single exponential fits to the charge recovery curves starting $4 \mathrm{msec}$ after the synaptic stimulation $(5.8 \pm 1.4 \mathrm{msec} ; p=$ $0.657 ; n=7)$. This was significantly faster than the decay of the
Bergmann glia AMPA receptor response recorded with a somatic recording electrode $(8.4 \pm 1.0 \mathrm{msec} ; p=0.004 ; n=7)$, demonstrating that there is some filtering of the conductance (a $42 \%$ slowing of the decay). The average time constant for the charging of the membrane at the active conductance was $4.4 \pm 1.9 \mathrm{msec}$, indicating the average conductance is electrotonically distant from the soma. This is consistent with the observation that most of the climbing fiber synaptic contacts are out in the dendritic tree of the Purkinje cell (Palay and Chan-Palay, 1974) and with the filtering of the decay time course.

Our estimation of the transmitter concentration reaching the Bergmann glial membranes depends on our somatic measurement of the amplitude ratio of the receptor responses in the presence and absence of CTZ. Although taking a ratio eliminates concerns of a uniform error in the amplitude measurement, the slowing and large increase in amplitude of the AMPA receptor response in CTZ may lead to differential amounts of filtering and voltage escape. We were unable to apply the voltage jump analysis to the Bergmann responses under control conditions because of their small size and variability. Therefore, we used the information on filtering gained from the voltage jump analysis in CTZ to construct a simple NEURON simulation addressing these concerns.

The model was constructed based on the general morphology of Bergmann glial cells (Palay and Chan-Palay, 1974; de Blas, 1984), the passive response of the cells to a square current injection, and the extent of filtering indicated by the voltage jump analysis. The inclusion of end feet with a conductance five times higher than the rest of the cell (Newman, 1986) was critical in reproducing the electrical properties of the Bergmann glia. Holding the other model parameters constant, the synaptic conductance kinetics and maximum value were altered so that the simulated AMPA receptor responses monitored at the soma matched the experimental data in the presence and absence of CTZ (Fig. 7). The unfiltered current flowing at the conductance under perfect voltage clamp can by calculated by the NEURON simulation. The perfectly clamped synaptic current peaked at 207-217 pA (see Materials and Methods) in control (experimental value recorded at soma, $34 \mathrm{pA}$ ) (Fig. $7 A$ ) and $1850 \mathrm{pA}$ in $\mathrm{CTZ}$ (experimental value recorded at soma, $286 \mathrm{pA}$ ) (Fig. 7B). Accounting for cable filtering and voltage escape, the fold increase in the amplitude of the AMPA receptor response with CTZ should be adjusted from 8.4-fold (corresponding to $192 \mu \mathrm{M}$ ) to 8.5- to 8.9-fold, indicating a range of 160-186 $\mu \mathrm{M}$ glutamate on the ratio curve.

\section{An AMPA receptor kinetic model}

An untested assumption in the preceding analysis is that the dose-response relationships constructed from rapid applications of glutamate to outside-out patches accurately represent receptor activation by synaptically released glutamate in situ. For instance, if the rise time of the synaptic glutamate transient is longer than that at the patch membrane, the dose-response relationship in control conditions may be significantly altered by rapid desensitization. To address this issue, we have modified a simple kinetic model of the AMPA receptor (Diamond and Jahr, 1997) to fit the data from Bergmann glia patches and then used the model to determine a driving function representing the synaptic glutamate transient that produces responses that fit the Bergmann glia climbing fiber response. The model replicates both the kinetics (Bergles et al., 1997) and amplitudes of the patch responses over a wide glutamate concentration range (Fig. 8). To fit the CTZ 
A

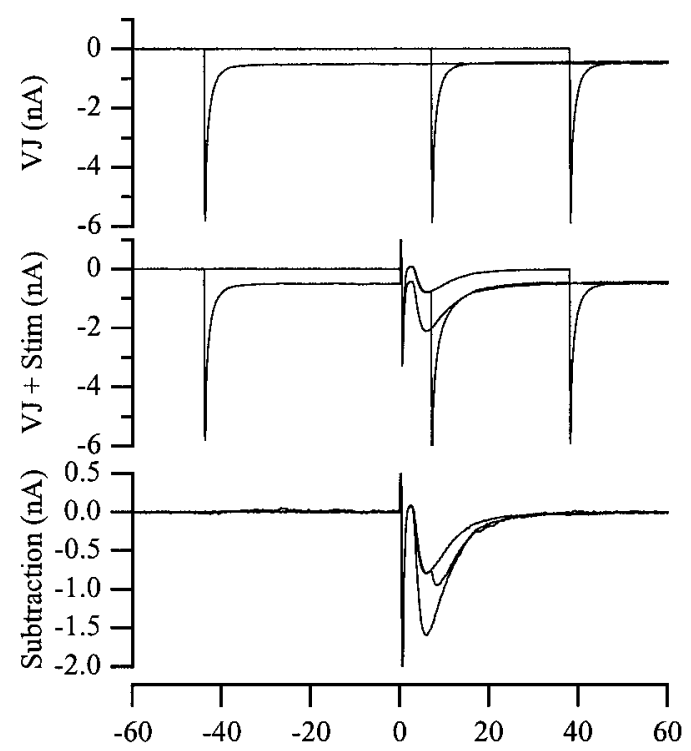

B

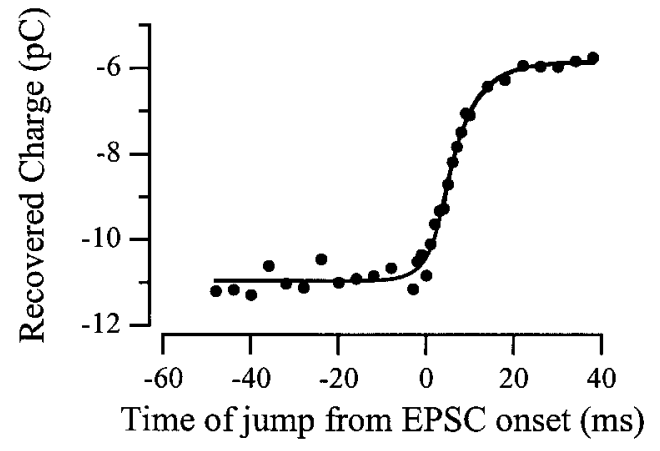

$\mathrm{C}$

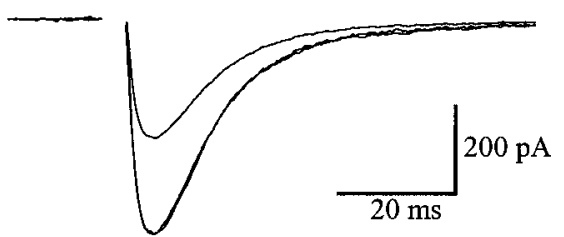

Figure 6. Voltage jump analysis of the Bergmann glia response. A, Three example time points superimposed to illustrate the voltage jump protocol. Top, Currents resulting from jumping the holding voltage from -50 to $-80 \mathrm{mV}$ at $-44,8$, and $38 \mathrm{msec}$ relative to the stimulus time point. Middle, The command voltages are the same, and climbing fiber stimulation is added at $t=0$. Bottom, Subtractions of the currents in the top panel from the middle panel. These are integrated to calculate the charge transferred. These experiments were performed in the presence of $200 \mu \mathrm{M}$ CTZ to maximize the amount of charge recovered. $B$, The resulting charge recovery curve fit with the full analytical function (see Materials and Methods) and with a single exponential fit to the data to the right of $3 \mathrm{msec}$. The $\tau_{\text {voltage }}$ was $3.2 \mathrm{msec}$, the $\tau_{\text {decay }}$ was $6.0 \mathrm{msec}$, and the single exponential fit gave a $\tau$ of $5.5 \mathrm{msec}$. A single exponential fit to the average response recorded at the soma had a time constant of $6.6 \mathrm{msec}$. $C$, Averages of five responses at -50 and -80 $\mathrm{mV}$. The response at $-50 \mathrm{mV}$ is also scaled up to the peak of the $-80 \mathrm{mV}$ response to compare their time course.

patch data, the unbinding rate was slowed from 16 to 6 per millisecond, and the rates into both desensitized states were zeroed. The ratio of the modeled dose-response curves is in close agreement with the patch data, giving an 8.4-fold increase at $205 \mu \mathrm{M}$.

A "synaptic" glutamate transient was approximated using a ramp rising phase to a given concentration and a single exponential falling phase. The rise time, peak concentration, and decay time were altered to fit the climbing fiber responses recorded in control and in the presence of CTZ. First, the rise and decay times of the glutamate transient were varied to fit the kinetics of the Bergmann glia responses while keeping the peak concentration at $190 \mu \mathrm{M}$. A rise time (time-to-peak) of $1.2 \mathrm{msec}$ and a decay time constant of $10 \mathrm{msec}$ fitted the climbing fiber responses in both conditions. Both the rising phase of the synaptic responses (Fig. 9) and the decay times (simulations not shown) were very sensitive to alterations in the kinetics of the driving function. Although changing the peak concentration of the glutamate driving function did not greatly alter the kinetics of the synaptic responses, the amplitude ratio of 8.4 was obtained with a peak concentration of $190 \mu \mathrm{M}$. The amplitude ratio versus concentration relationship of the modeled synaptic conductances was less steep than either the ratio of the patch data or the simulated patch data. Nevertheless, $300 \mu \mathrm{M}$ yielded a ratio of 7.8, whereas $100 \mu \mathrm{M}$ resulted in a ratio of 9 . Thus, whereas the sensitivity was lower, the amplitude ratio was still well defined. Clearly, this model oversimplifies the gating mechanism underlying the AMPA receptor currents. However, the modeling does suggest that the method used to estimate the average peak concentration of glutamate at Bergmann glia membranes is not greatly degraded by the ambiguities introduced by desensitization.
A
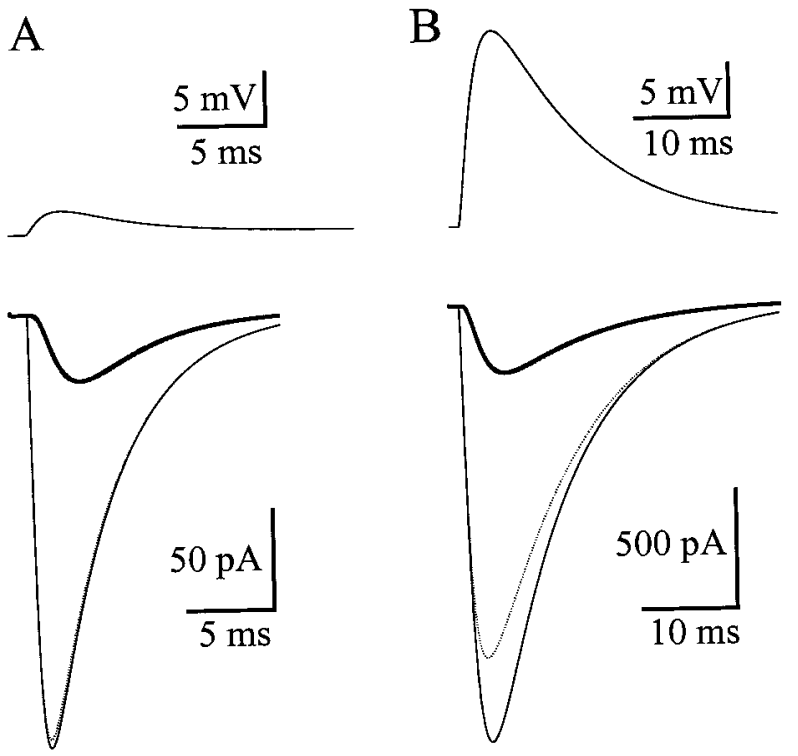

Figure 7. Simulation of somatic recordings of the Bergmann glia AMPA receptor responses. $A$, Simulated recordings under control conditions. Top, Membrane voltage at the synapse. Bottom, Current measured at the soma (thick line), flowing at the synapse (dotted line), and flowing at the synapse under perfect voltage clamp (thin line). $B$, Simulated recordings in the presence of CTZ. Top, Membrane voltage at the synapse. Bottom, Current measured at the soma (thick line), flowing at the synapse (dotted line), and flowing at the synapse under perfect voltage clamp (thin line). 
A

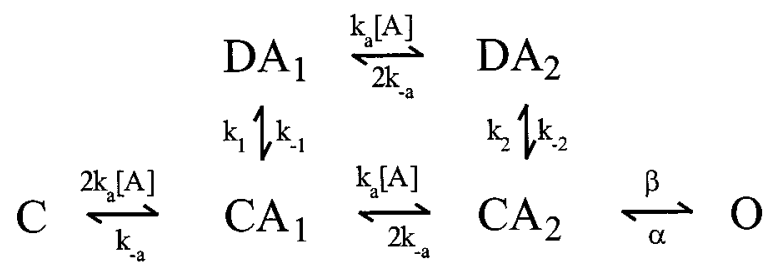

B
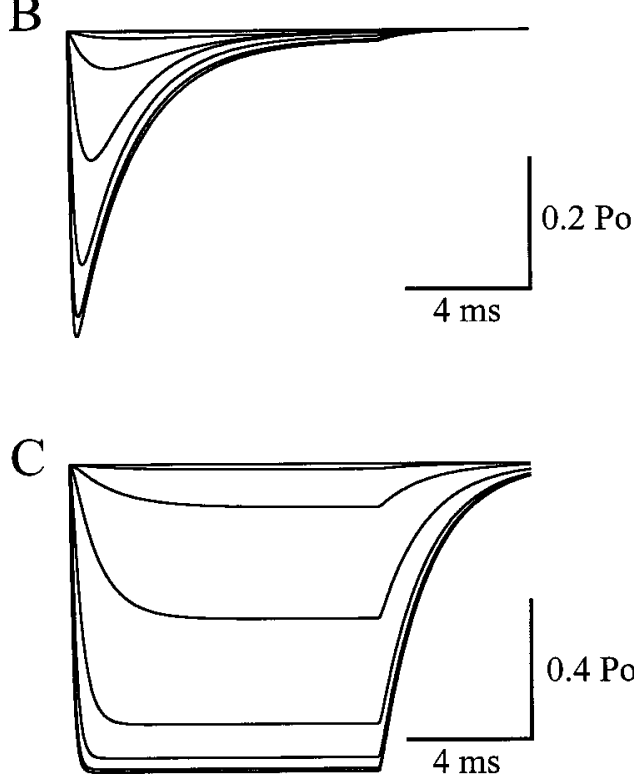

$\mathrm{D}$

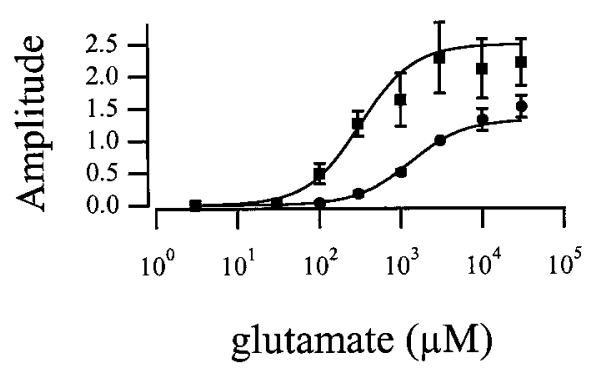

$\mathrm{E}$

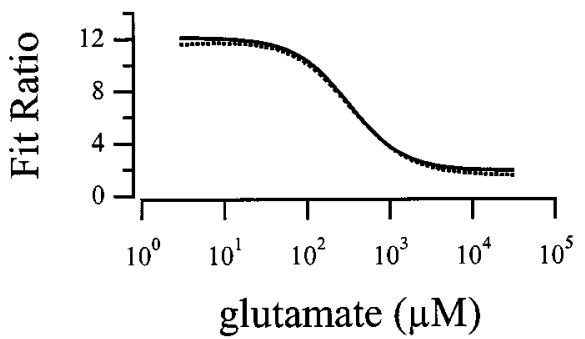

Figure 8. Simulations of AMPA receptor responses to brief applications of glutamate. $A$, State diagram used to reproduce AMPA receptor kinetics. Rates were as follows [units are micromolar per millisecond (for $k_{\mathrm{a}}$ ) or per millisecond]: $k_{\mathrm{a}}, 0.009 ; k_{-\mathrm{a}}, 16.0$ (6.0 in cyclothiazide); $k_{-1}, 0.0025 ; k_{2}, 5.0$; $k_{-2}, 0.006$ ( 0 in cyclothiazide); $\alpha, 1.3 ; \beta, 13.0 . k_{1}$ was set to 2.08 ( 0 in cyclothiazide) to satisfy microscopic reversibility. $B$, Simulated responses to 10 msec pulses of glutamate at $0.1,0.3,1.0,3.0,10.0$, and $30.0 \mathrm{~mm}$. $C$, Simulated responses to 10 msec pulses of glutamate at the same concentrations as in $B$ but with $k_{-a}$ set to $6 \mathrm{msec}$ and $k_{1}$ and $k_{2}$ set to 0 to mimic the effects of cyclothiazide. $D$, Simulated dose-response curves superimposed on the data from Figure $5 A$. E, The amplitude ratio of the CTZ simulation over the control simulation plotted against concentration (solid line). The ratio of the logistic fits to the patch data given in Figure 5 is superimposed (dotted line).

\section{DISCUSSION}

Our results, indicating that $160-190 \mu \mathrm{M}$ glutamate reaches the Bergmann glia membrane after climbing fiber stimulation, depend on the modulation of the Bergmann glia AMPA receptor response by CTZ. CTZ has been shown to greatly reduce desensitization and to increase the apparent affinity of the AMPA receptors (Patneau et al., 1993; Yamada and Tang, 1993; Partin et al., 1994, 1996). The mechanism of its action is not completely understood but is thought to occur via a destabilization of the desensitized state or a stabilization of the closed nondesensitized state (Trussell et al., 1993, 1994; Yamada and Tang, 1993; Partin et al., 1994, 1996). The important property of the action of CTZ for this study is that it produced a concentration-dependent increase in the response of the receptors. This allowed the quantification of the glutamate concentration at the Bergmann glia membrane by comparing the CTZ-induced increase of the synaptic response with that of the patch responses to a range of glutamate concentrations.

In contrast to Bergmann glia responses, the amplitudes of Purkinje cell EPSC and patch responses were not altered by CTZ. This result is similar to that of Dittman and Regehr (1998), who found that climbing fiber-EPSC peak amplitudes measured in Purkinje cells were slightly reduced by CTZ. The high concentrations of glutamate in the Purkinje cell experiments $(>1 \mathrm{~mm}$ in the cleft, and $3 \mathrm{~mm}$ for patches) can partially explain this result, because an increase in affinity would have less effect near saturation. However, even at the top of the dose-response curve, there was a fifty percent increase in the Bergmann glia patch response. This difference between Purkinje cell patch and Bergmann glia patch responses may be caused, in part, by the faster desensitization kinetics of the Bergmann AMPA receptors leading to more desensitization at the peak of the response in control conditions. In addition, AMPA receptors are susceptible to channel block by CTZ, the magnitude of which may be altered by different subunit combinations (Patneau et al., 1993; Stern-Bach et al., 1998).

The observation that CTZ increased the peak amplitude of the Bergmann glia climbing fiber response to the same degree at 35 and $25^{\circ} \mathrm{C}(740 \pm 150$ vs $840 \pm 240 \% ; p=0.53)$ suggests that a similar peak concentration of glutamate reaches the glial AMPA receptors at the two temperatures. Despite the strong temperature dependence of transport (Wadiche et al., 1995), it is possible that the initial bolus of glutamate that reaches nearby Bergmann glia AMPA receptors is relatively unaffected by the faster transport at physiological temperatures. The turnover time for glutamate transporters at elevated temperatures may be as fast as 12 msec (Bergles and Jahr, 1998), much slower than the time to peak of the Bergmann glia AMPA receptor response at $35^{\circ} \mathrm{C}(\sim 2$ $\mathrm{msec})$. Therefore, although binding of glutamate by transporters 
A Control

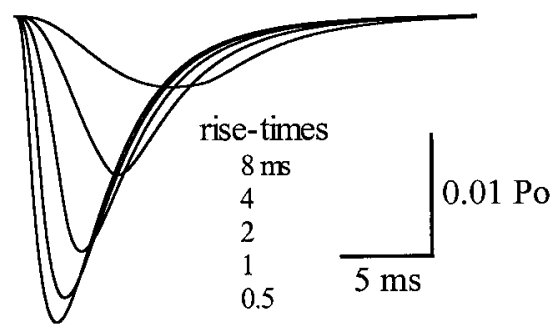

B

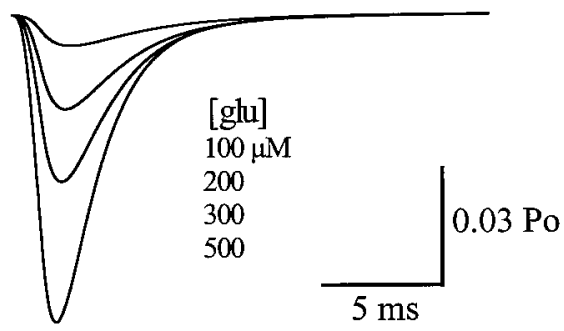

Cyclothiazide

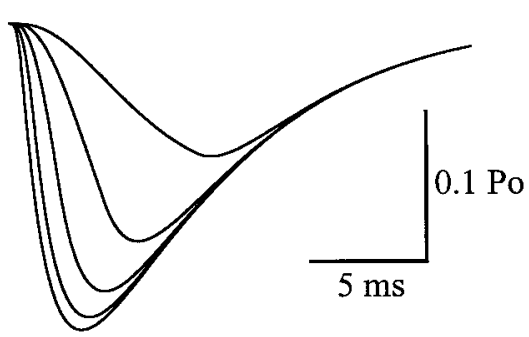

Figure 9. Simulated Bergmann glia responses to synaptically released glutamate. $A$, Synaptic simulations in control $\left(k_{-\mathrm{a}}, 16.0 \mathrm{msec}\right)$ and cyclothiazide $\left(k_{-\mathrm{a}}\right.$, $6.0 \mathrm{msec} ; k_{1}$ and $k_{2}$ set to 0 ) with rise time of the driving function (glutamate transient) set to $0.5,1,2,4$, and 8 msec. Decay time constant was set at $10 \mathrm{msec}$ and peak concentration at $190 \mu \mathrm{M}$. $B$, Synaptic simulations in control and cyclothiazide as in $A$ with the peak concentration set to $100,200,300$, and $500 \mu \mathrm{M}$. Decay time constant was $10 \mathrm{msec}$, and the rise time was $1.2 \mathrm{msec}$. expressed by both Purkinje cells and Bergmann glia undoubtedly lowers the concentration of glutamate reaching Bergmann glial AMPA receptors, it is unlikely that the binding capacity during the response rise time will be significantly altered by the increased transporter cycling rate at higher temperatures. It would appear, then, that the initial wave of glutamate reaching the Bergmann glia AMPA receptors is too fast to be altered significantly by elevating temperature to near physiological values.

The variability in the degree of potentiation by CTZ of the Bergmann glia AMPA response $(840 \pm 240 \% ; n=8)$ may indicate some biological variability in the concentration of glutamate seen by the Bergmann glia. The spatial arrangement of the receptors around the cleft, the degree of synapse envelopment, the maturity of the cell being recorded from, and other factors may vary from cell to cell and give rise to different average concentrations seen by a given Bergmann glia. Interestingly, in searching for the primary all-or-none climbing fiber response in the Bergmann glia, there was occasionally a secondary all-or-none input. Because Bergmann glia processes are not planar like Purkinje cell dendrites (de Blas, 1984), each Bergmann glial cell may interact with more than one climbing fiber.

Previously CTZ has been linked to an increase in the probability of release at some synapses (Barnes-Davies and Forsythe, 1995; Diamond and Jahr, 1995; but see Mennerick and Zorumski, 1995; Isaacson and Walmsley, 1996). In contrast, we show here that the climbing fiber release probability was not significantly altered by CTZ. This difference might be explained by the high release probability of the climbing fiber terminal (Dittman and Regehr, 1998; Silver et al., 1998). The strong paired-pulse depression seen at this synapse, along with little increase in synaptic strength with elevated external calcium, indicate that release probability is near maximal (Dittman and Regehr, 1998; Silver et al., 1998). Consistent with our results, Dittman and Regehr (1998) recently showed little effect of CTZ on the paired-pulse ratio of climbing fiber-evoked EPSCs recorded in Purkinje cells. The presynaptic action of CTZ on terminals with a low probability of release was confirmed in one of our Purkinje cell recordings in which we monitored the effects of CTZ on a parallel fiber input. These inputs have a low release probability, as demonstrated by their paired-pulse facilitation (Atluri and Regehr, 1996). In contrast to the climbing fiber-evoked response in Purkinje cells, the parallel fiber EPSCs increased approximately sixfold, and the paired-pulse ratio switched from facilitation to depression in CTZ. The variability in the presynaptic effects of CTZ with different pathways may also reflect differential expression of CTZ receptivity in the terminals.

In the presence of CTZ, we estimate that the Bergmann glia AMPA receptor conductance decays with a time constant of 6 msec. This should reflect the decay of the glutamate concentration at these receptors because there is no desensitization in CTZ and the intrinsic kinetics of the receptors are rapid. This is faster but not inconsistent with our previous report of a $17 \mathrm{msec}$ decay of extrasynaptic glutamate based on the Bergmann glia transporter current (Bergles et al., 1997). Our current estimate is in part faster because it accounts for the cable filtering and voltage escape inherent in somatic voltage-clamp recordings. In addition, the lower apparent affinity of the AMPA receptors would make them less sensitive than the transporters to reduced concentrations of glutamate diffusing to more distant areas. It is also possible that the AMPA receptors may be more localized to the membranes surrounding the synaptic clefts (Baude et al., 1994), whereas the transporters may cover more surface area of the Bergmann glia.

The main result of this paper is that glutamate escapes from the climbing fiber-Purkinje cell cleft and can reach perisynaptic membranes at concentrations of 160-190 $\mu \mathrm{M}$. This concentration is sufficient to activate all classes of glutamate receptors, including metabotropic, NMDA, and non-NMDA receptors. There is a 
growing body of evidence indicating that synaptic transmission can be modulated by glutamate that escapes from the synaptic cleft (Clarke et al., 1997; Forsythe and Barnes-Davies, 1997; Scanziani et al., 1997). There is also evidence that the highaffinity NMDA receptors at one synapse may sense glutamate released from neighboring synapses (Kullmann and Asztely, 1998; Rusakov and Kullmann, 1998). The results presented here demonstrate a basic requirement of both of these phenomena, that glutamate can escape the synaptic cleft and reach the surrounding membranes at a concentration sufficient to activate glutamate receptors. This alters the standard view of the actions of glutamate in the CNS, expanding the sphere of influence of synaptically released glutamate beyond the postsynaptic membrane.

\section{REFERENCES}

Asztely F, Erdemli G, Kullmann DM (1997) Extrasynaptic glutamate spillover in the hippocampus: dependence on temperature and the role of active glutamate uptake. Neuron 18:281-293.

Atluri PP, Regehr WG (1996) Determinants of the time course of facilitation at the granule cell to purkinje cell synapse. J Neurosci 16:5661-5671.

Barnes-Davies M, Forsythe ID (1995) Pre- and postsynaptic glutamate receptors at a giant excitatory synapse in rat auditory brainstem slices. J Physiol (Lond) 488:387-406.

Baude A, Molnar E, Latawiec D, McIlhinney RA, Somogyi P (1994) Synaptic and nonsynaptic localization of the GluR1 subunit of the AMPA-type excitatory amino acid receptor in the rat cerebellum. J Neurosci 14:2830-2843.

Bergles DE, Jahr CE (1997) Synaptic activation of glutamate transporters in hippocampal astrocytes. Neuron 19:1297-1308.

Bergles DE, Jahr CE (1998) Glial contribution to glutamate uptake at Schaffer collateral-commissural synapses in the hippocampus. J Neurosci 18:7709-7716.

Bergles DE, Dzubay JA, Jahr CE (1997) Glutamate transporter currents in Bergmann glial cells follow the time course of extrasynaptic glutamate. Proc Natl Acad Sci USA 94:14821-14825.

Clark BA, Barbour B (1997) Currents evoked in Bergmann glial cells by parallel fibre stimulation in rat cerebellar slices. J Physiol (Lond) 502:335-350.

Clarke VR, Ballyk BA, Hoo KH, Mandelzys A, Pellizzari A, Bath CP, Thomas J, Sharpe EF, Davies CH, Ornstein PL, Schoepp DD, Kamboj RK, Collingridge GL, Lodge D, Bleakman D (1997) A hippocampal GluR5 kainate receptor regulating inhibitory synaptic transmission. Nature 389:599-603.

Clements JD (1996) Transmitter timecourse in the synaptic cleft: its role in central synaptic function. Trends Neurosci 19:163-171.

Clements JD, Lester RA, Tong G, Jahr CE, Westbrook GL (1992) The time course of glutamate in the synaptic cleft. Science 258:1498-1501.

de Blas AL (1984) Monoclonal antibodies to specific astroglial and neuronal antigens reveal the cytoarchitecture of the Bergmann glia fibers in the cerebellum. J Neurosci 4:265-273.

Diamond JS, Jahr CE (1995) Asynchronous release of synaptic vesicles determines the time course of the AMPA receptor-mediated EPSC. Neuron 15:1097-1107.

Diamond JS, Jahr CE (1997) Transporters buffer synaptically released glutamate on a submillisecond time scale. J Neurosci 17:4672-4687.

Dittman JS, Regehr WG (1998) Calcium dependence and recovery kinetics of presynaptic depression at the climbing fiber to Purkinje cell synapse. J Neurosci 18:6147-6162.

Forsythe ID, Barnes-Davies M (1997) Synaptic transmission: wellplaced modulators. Curr Biol 7:R362-R365.

Häusser M, Roth A (1997) Estimating the time course of the excitatory synaptic conductance in neocortical pyramidal cells using a novel voltage jump method. J Neurosci 17:7606-7625.
Hines M (1993) NEURON: a program for simulation of nerve equations. In: Neural systems: analysis and modeling, (Eeckman FH, ed), pp 127-136. Boston: Kluwer.

Isaacson JS, Walmsley B (1996) Amplitude and time course of spontaneous and evoked excitatory postsynaptic currents in bushy cells of the anteroventral cochlear nucleus. J Neurophysiol 76:1566-1571.

Kanai Y, Smith CP, Hediger MA (1993) The elusive transporters with a high affinity for glutamate. Trends Neurosci 16:365-370.

Kullmann DM, Asztely F (1998) Extrasynaptic glutamate spillover in the hippocampus: evidence and implications. Trends Neurosci 21:8-14.

Lester RA, Jahr CE (1992) NMDA channel behavior depends on agonist affinity. J Neurosci 12:635-643.

Mennerick S, Zorumski CF (1995) Presynaptic influence on the time course of fast excitatory synaptic currents in cultured hippocampal cells. J Neurosci 15:3178-3192.

Newman EA (1986) High potassium conductance in astrocyte endfeet. Science 233:453-454.

Nicholls D, Attwell D (1990) The release and uptake of excitatory amino acids. Trends Pharmacol Sci 11:462-468.

Palay SL, Chan-Palay V (1974) The neuroglial cells of the cerebellar cortex and the climbing fiber. In: Cerebellar cortex cytology and organization (Palay SL, Chan-Palay V, eds), pp 288-321. New York: Springer.

Partin KM, Patneau DK, Mayer ML (1994) Cyclothiazide differentially modulates desensitization of $\alpha$-amino-3-hydroxy-5-methyl-4isoxazolepropionic acid receptor splice variants. Mol Pharmacol 46:129-138.

Partin KM, Fleck MW, Mayer ML (1996) AMPA receptor flip/flop mutants affecting deactivation, desensitization, and modulation by cyclothiazide, aniracetam, and thiocyanate. J Neurosci 16:6634-6647.

Patneau DK, Vyklicky Jr L, Mayer ML (1993) Hippocampal neurons exhibit cyclothiazide-sensitive rapidly desensitizing responses to kainate. J Neurosci 13:3496-3509.

Pearce RA (1993) Physiological evidence for two distinct GABAA responses in rat hippocampus. Neuron 10:189-200.

Rothstein JD, Martin L, Levey AI, Dykes-Hoberg M, Jin L, Wu D, Nash N, Kuncl RW (1994) Localization of neuronal and glial glutamate transporters. Neuron 13:713-725.

Rusakov DA, Kullmann DM (1998) Extrasynaptic glutamate diffusion in the hippocampus: ultrastructural constraints, uptake, and receptor activation. J Neurosci 18:3158-3170.

Scanziani M, Salin PA, Vogt KE, Malenka RC, Nicoll RA (1997) Usedependent increases in glutamate concentration activate presynaptic metabotropic glutamate receptors. Nature 385:630-634.

Silver RA, Momiyama A, Cull-Candy SG (1998) Locus of frequencydependent depression identified with multiple-probability fluctuation analysis at rat climbing fibre-Purkinje cell synapses. J Physiol (Lond) 510:881-902.

Stern-Bach Y, Russo S, Neuman M, Rosenmund M (1998) A point mutation in the glutamate binding site blocks desensitization of AMPA receptors. Neuron 21:907-918.

Tong G, Jahr CE (1994) Block of glutamate transporters potentiates postsynaptic excitation. Neuron 13:1195-1203.

Trussell LO, Zhang S, Raman IM (1993) Desensitization of AMPA receptors upon multiquantal neurotransmitter release. Neuron 10:1185-1196.

Trussell LO, Raman IM, Zhang S (1994) AMPA receptors and rapid synaptic transmission. Semin Neurosci 6:71-79.

Wadiche JI, Arriza JL, Amara SG, Kavanaugh MP (1995) Kinetics of a human glutamate transporter. Neuron 14:1019-1027.

Yamada KA, Tang CM (1993) Benzothiadiazides inhibit rapid glutamate receptor desensitization and enhance glutamatergic synaptic currents. J Neurosci 13:3904-3915.

Zerangue N, Kavanaugh MP (1996) Flux coupling in a neuronal glutamate transporter. Nature 383:634-637. 